Древицкая Оксана Остаповна - доктор медицинских наук, доцент, заведующая кафедрой медицинской психологии ЧАО «ВУЗ «Межрегиональная Академия управления персоналом»; 02000, ул. Фрометовская, 2, г. Киев, Украина; drevitska@ukr.net; +38(067) 702-45-90

ORCID ID 0000-0002-1551-9329

Филатова Оксана Аркадьевна - доктор медицинских наук, доцент, профессор кафедры медицинской психологии ЧАО «ВУЗ «Межрегиональная Академия управления персоналом»; 02000, ул. Фрометовская, 2, г. Киев, Украина; hlaalu@ukr.net +38 (067) 755-90-00

ORCID ID 0000-0002-1551-9329

\title{
КОРРЕКЦИЯ ПСИХОЭМОЦИОНАЛЬНОГО СОСТОЯНИЯ ЖЕНЩИН, ОБРАТИВШИХСЯ В ЖЕНСКУЮ КОНСУЛЬТАЦИЮ ПО ПОВОДУ ПРЕРЫВАНИЯ БЕРЕМЕННОСТИ
}

\begin{abstract}
Анотація
Древіцька О.О. - доктор медичних наук, доцент, завідувач кафедри медичної психології ПРАТ «ВНЗ «МАУП»; Філатова О. А. - доктор медичних наук, доцент, професор кафедри медичної психології ПРАТ «ВНЗ «МАУП»; м. Київ, Україна. Корекція психоемоційного стану жінок, які звернулися до жіночої консультації 3 приводу переривання вагітності.

Ключові слова: вагітні, постабортний синдром, психологічна корекція

Постановка проблеми. Під час вагітності зростає емоційність жінки, і коли інтенсивність переживань поєднується з несприятливим мікросоціальним
\end{abstract}


середовищем, кар'єрними проблемами, погіршенням загального самопочуття, деякі жінки зважуються на штучне переривання вагітності, а згодом у них з'являються думки про можливе безпліддя, викидні, настання позаматкової вагітності та ін., що потребує відповідної медико-психологічної допомоги.

Аналіз останніх досліджень i публікацій. Про психологічний постабортний синдром, що розвивається після штучного переривання вагітності, мало говориться в наукових і популярних публікаціях. Синдром супроводжується почуттям провини, втрати, депресивними, тривожними, фобічними розладами. Незважаючи на успіхи сучасної гінекології, питання психопрофилактики порушеного емоційного стану у вагітних на сьогодні ще недостатньо вивчені.

Формулювання мети статті. Мета роботи - вивчити особливості психоемоційного стану жінок, які звернулися з приводу переривання вагітності, для розробки відповідної програми та психокорекції.

Виклад основного матеріалу. Вивчення психоемоційного стану вагітних жінок, які звернулися в жіночу консультацію з приводу переривання вагітності, показало наявність високих показників ситуативної та особистісної тривожності. Корекція психоемоційного стану вагітної жінки при настанні незапланованої вагітності є необхідною, оскільки може зменшити тривожність, попередити афективний тип мислення і прийняття рішень, може сприяти збереженню вагітності і профілактиці постабортного синдрому.

Висновки та перспективи подальших досліджень. Психологічна корекція необхідна для стабілізації психоемоційного стану вагітних, їх зваженої поведінки та профілактики розвитку постабортного синдрому. Дана тематика вимагає подальших досліджень і підвищення рівня психологічної культури вагітних. 


\section{Аннотация}

Древицкая О. О. - доктор медицинских наук, доцент, заведующая кафедрой медицинской психологии ЧАО «ВУЗ «МАУП»; Филатова О. А. - доктор медицинских наук, доцент, профессор кафедры медицинской психологии ЧАО «ВУЗ «МАУП»; г. Киев, Украина. Коррекция психоэмоционального состояния женщин, обратившихся в женскую консультацию по поводу прерывания беременности.

Ключевые слова: беременные, постабортный синдром, психологическая коррекция.

Постановка проблемы. Во время беременности возрастает эмоциональность женщины, и когда интенсивность переживаний сочетается с неблагоприятной микросоциальной средой, карьерными проблемами, ухудшением общего самочувствия, некоторые женщины решаются на искусственное прерывание беременности, а затем у них появляются мысли о возможном бесплодии, выкидыше, наступлении внематочной беременности и др., что требует соответствующей медико-психологической помощи.

Анализ последних исследований и публикаций. О психологическом постабортном синдроме, развивающемся после искусственного прерывания беременности, мало говорится в научных и популярных публикациях. Синдром сопровождается чувством вины, потери, депрессивными, тревожными, фобическими расстройствами. Несмотря на успехи современной гинекологии, вопросы психопрофилактики нарушенного эмоционального состояния у беременных на сегодня еще недостаточно изучены.

Формулировка цели статьи. Цель работы - изучить особенности психоэмоционального состояния женщин, обратившихся по поводу прерывания беременности, для разработки соответствующей программы и психокоррекции. 
Изложение основного материала. Изучение психоэмоционального состояния беременных женщин, обратившихся в женскую консультацию по поводу прерывания беременности, показало наличие высоких показателей ситуативной и личностной тревожности. Коррекция психоэмоционального состояния беременной женщины при наступлении незапланированной беременности является необходимой, поскольку может уменьшить тревожность, предупредить аффективный тип мышления и принятия решений, может способствовать сохранению беременности и профилактике постабортного синдрома.

Выводы и перспективы дальнейших исследований. Психологическая коррекция необходима для стабилизации психоэмоционального состояния беременных, их взвешенного поведения и профилактики развития постабортного синдрома. Данная тематика требует дальнейших исследований и повышения уровня психологической культуры беременных.

\section{Annotation}

Drevitska O.O. - PhD, MD, Associate Professor, Head of The Medical Psychology Department, The Private Joint-Stock Company "Higher Educational Institution "Interregional Academy of Personnel Management"; Filatova O. A. - PhD, MD, Associate Professor, Professor of The Medical Psychology Department, The Private Joint-Stock Company "Higher Educational Institution "Interregional Academy of Personnel Management"; Kyiv, Ukraine. Correction Psychoemotional State of Women, wich was taken Gynecological Consultation on the Interruption of Pregnancy.

Key words: pregnancy, postabortion syndrome, psychological correction

Formulation of the problem. The emotionality of women increases during pregnancy, and when the intensity of emotionality is combined with unfavorable 
microsocial environment, career problems, deterioration of general well-being, some women are judged to be artificially aborted, and later they have thoughts about possible infertility, miscarriage, an ectopic pregnancy, etc., which requires appropriate medical and psychological assistance.

Analysis of recent research and publications. The psychological postabortion syndrome that develops after abortion is little mentioned in scientific and popular publications. The syndrome is accompanied by a sense of guilt, loss, depression, anxiety, phobic disorders. Despite the successes of modern gynecology, the issue of psychoprophylaxis of an impaired emotional state in pregnant women has not yet been sufficiently studied.

Formulating the purpose of the article. The purpose of the work is to study the features of the psycho-emotional state of women who have applied for abortion, to develop an appropriate program and psycho-correction.

The presentation of the main material. The study of the psycho-emotional state of pregnant women who sought women's advice on abortion, showed the presence of high rates of situational and personal anxiety. Correction of the psychoemotional state of a pregnant woman during an unplanned pregnancy is necessary because it can reduce anxiety, prevent affective thinking and decision-making, can help preserve pregnancy and prevent post-abortion syndrome.

Conclusions and prospects for further research. Psychological correction is necessary to stabilize the psycho-emotional state of pregnant women, their wise behavior and prevent the development of post-abortion syndrome. This topic requires further research and raising the level of psychological culture of pregnant women.

Ключевые слова: беременные, постабортный синдром, психологическая коррекция. 
Постановка проблемы. Проблема сохранения здоровья матери и ребенка является одной из приоритетных в современном украинском обществе. Перманентная сложная социально-экономическая ситуация, снижение комфортности и стабильности влияют на мотивацию молодых женщин к осознанному материнству $[1,2]$.

Анализ последних исследований и публикаций. Как известно, эмоциональность женщины во время беременности возрастает. Чаще всего женщин одолевают сомнения по поводу здоровья будущего ребенка, возможности благополучного вынашивания и родов, а также изменения своего физического облика. Многие из этих и других переживаний происходят от незнания физиологических и психологических аспектов течения беременности, наличия огромного количества предрассудков, а также по причине повышенной внушаемости женщин в этом состоянии $[3,4]$.

В случаях, когда интенсивность переживаний достигает максимума, сочетаясь с неблагоприятной микросоциальной обстановкой, карьерными проблемами, ухудшением общего самочувствия, часть женщин решается на искусственное прерывание беременности, а впоследствии у них появляются мысли о возможном бесплодии, выкидышах, наступлении внематочной беременности, воспалительных заболеваниях генитальной сферы, сексуальных нарушениях. Развивается психологический постабортный синдром, о котором мало говорится в научных и популярных публикациях. Синдром сопровождается чувством вины, невозвратимой потери, пограничными психическими расстройствами - депрессивными, тревожными, фобическими [5-7].

Несмотря на успехи современной гинекологии и улучшение медицинского обслуживания женщин, использование современных обезболивающих средств и щадящие методы проводимого вмешательства, 
вопросы психопрофилактики нарушенного эмоционального состояния $\mathrm{y}$ беременных все ещё недостаточно изучены.

Формулирование цели статьи. Цель работы - изучить особенности психоэмоционального состояния женщин, обратившихся по поводу прерывания беременности, для разработки соответствующей программы психопрофилактики и психокоррекции.

Изложение основного материала. Материалы и методы исследования: в исследовании приняли участие 38 беременных женщин, наблюдавшихся в женской консультации КЗОЗ «Дергачевская центральная районная больница». Респондентки данной выборки обратились для прерывания беременности и были обследованы психологом с их добровольного согласия.

Для женщин экспериментальной группы использовали опросник, он состоял из следующих вопросов: «Какие эмоции и мысли посещали Вас, когда Вы узнали о своей беременности? Какие изменения в своём теле Вы почувствовали? Что изменится в Вашей жизни, если Вы оставите ребёнка?»

Использовались также следующие психодиагностические методики: клиническое интервью, тест "Диагностика ситуативной и личностной тревожности"Ч.Д. Спилбергера -Ю.Л. Ханина[8],рисуночный тест «Я и мой ребенок» (Г.Г. Филиповой).

В ходе беседы c женщинами экспериментальной группы перед процедурой прерывания беременности, были выявлены ряд соматических и вегетативных нарушений: волнение, сопровождающееся учащенным дыханием и потливостью; лабильность артериального давления, учащенное сердцебиение, особенно при обсуждении вопроса: «Что изменится, если Вы оставите ребенка?»; безразличие к еде; тянущие боли внизу живота.

Следовательно, решение об аборте часто принималось женщинами на фоне тревожных опасений, переживаний, направленных в будущее. 
Анализ рисуночного теста «Я и мой ребенок» выявил следующее: для женщин, которые предпочли прерывание беременности, преобладал конфликт с беременностью - у 78,1\% (рис. 1).

Этот результат указывал на отсутствие или фрагментарность формирования гестационной доминанты у исследованных пациенток, эмоциональную нестабильность, отсутствие установки на осознанное материнство.

Результаты диагностики ситуативной и личностной тревожности (Ч.Д. Спилбергера - Ю.Л.Ханина) показаны на рис. 2.

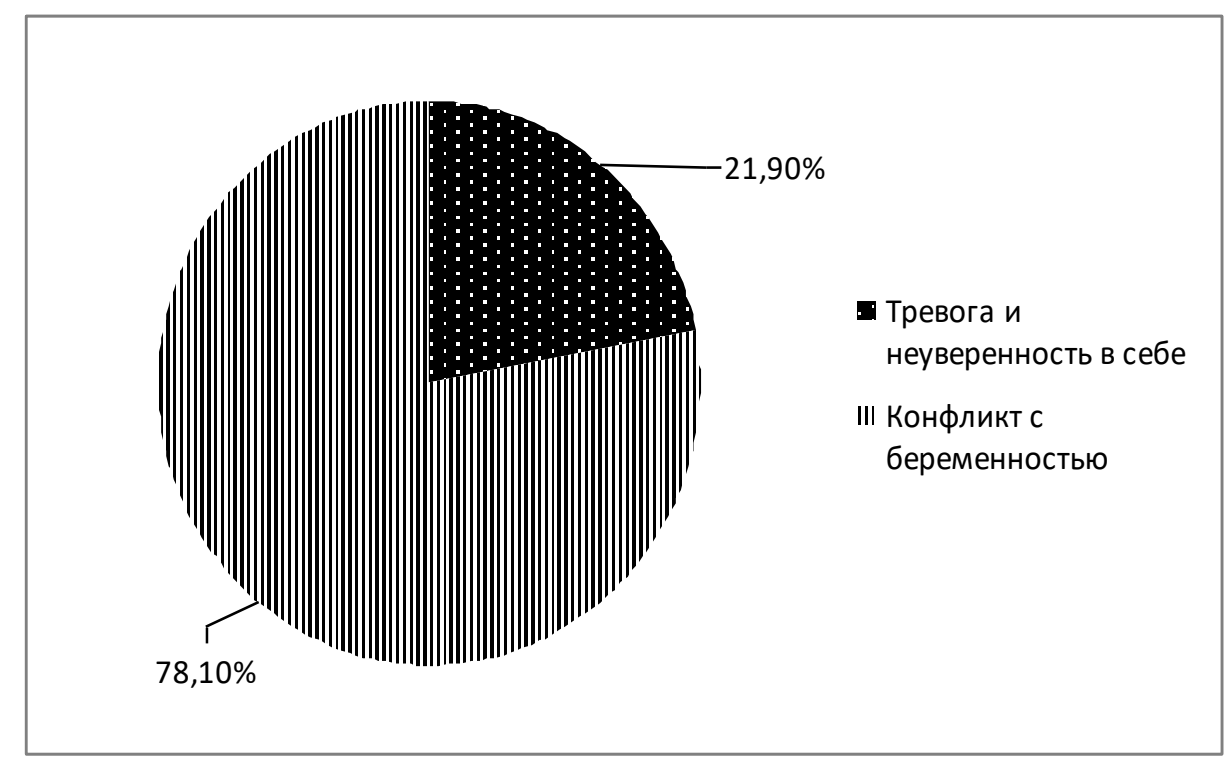

Рис. 1. Распределение женщин предпочитающих прервать беременность, по типам отношения к беременности, в \%. 


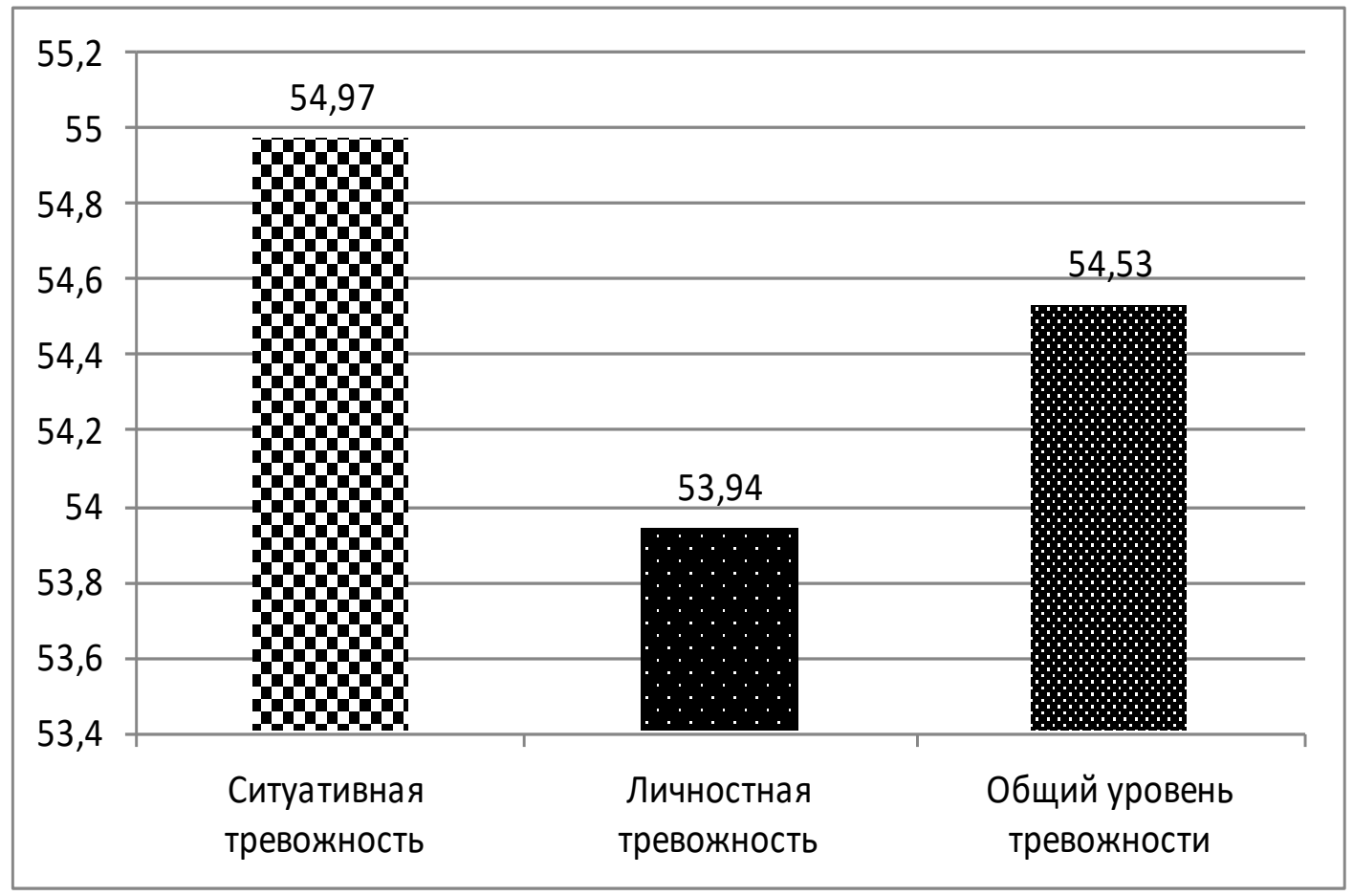

Рис.2. Выраженность показателей тревожности женщин перед прерыванием беременности, (в баллах, средний показатель).

Как видно на рис. 2, у женщин, которые обратились в женскую консультацию по поводу прерывания беременности, наиболее ярко выражена «ситуативная тревожность», связанная с конкретной внешней ситуацией. Однако, и личностная тревожность у обследованных была высокой. Этим можно объяснить тревогу связанную с незапланированной беременностью, частое развитие постабортного синдрома, а также склонность тревожных женщин к прерыванию последующих незапланированных беременностей. Снижение уровня тревожности в результате психокоррекционного комплекса может способствовать подготовке женщины к ситуации будущей беременности, формированию у нее установки на осознанное материнство, а также профилактике развития постабортного синдрома. По полученным результатам можно говорить о том, что в ситуации незапланированной беременности и/или отсутствия положительной установки на рождение ребенка, женщины требуют проведения психокоррекционой работы по стабилизации нарушений в 
эмоциональной сфере еще до прерывания беременности, поскольку высокая тревожность представляет собой предиктор неадаптивного поведения, принятия решений на основе аффектогенного мышления.

С учетом результатов обследования, была разработана программа психопрофилактической работы с беременными, она включала работу над коррекцией основных уровней «Внутренней картины беременности»: сенсорного, эмоционального, когнитивного, поведенческого и ценностного.

Апробация психокоррекционной программы была осуществлена с 18 беременными женщинами из числа обследованных. $\mathrm{C}$ ними было проведено по 6 встреч в малых группах (3-4 женщины), время ограничивалось от 1,5 до 2-х часов. Вначале направленность психологической коррекции была обращена на ценностный и когнитивно-поведенческий уровни, поскольку именно они определяют решение о вынашивании беременности. Выявляли истинную причину желания прервать беременность, проговаривали еe с позиций представления женщиной еe зрелого возраста. Имагинальная и арттерапевтические техники способствовали правильному для пациентки выбору. Коррекция сенсорного и эмоционального уровней предполагала устранение через аутотренинг неприятных опущений, вегетативной и эмоциональной нестабильности. После проведения психокоррекционной программы проведен контрольный срез, повторная диагностика, предусмотренная исследованием. После обработки данных, были получены следующие результаты: практически у всех женщин, входящих в группу психокоррекционной работы, наблюдалось изменение показателей в сторону их снижения, уменьшения глубины и интенсивности нарушений.

Анализируя полученные данные, можно отметить, что женщины после проведения психокоррекционных мероприятий стали более спокойными, прежние соматические жалобы на плохое самочувствие исчезли. Также 
отсутствовали жалобы на изменение настроения; наблюдалось повышение общего жизненного тонуса, появление положительного эмоционального состояния в связи с формированием у них многовариантного образа будущого, а также адекватной модели супружеских отношений и взаимных экспектаций в случае произведенного аборта. После проведенной психокоррекционной работы из18-ти ее участниц 4 женщины решили сохранить беременность. В итоге, после проведения психокоррекции, женщины были подготовлены к ситуации возможной очередной незапланированной беременности, у них была сформирована установка на осознанное материнство, проведена профилактика развития постабортного синдрома. Всё вышесказанное позволяет сделать вывод о том, что проведение психокоррекционной программы по предложенному алгоритму явлется необходимым для реализации в женской консультации.

Выводы и перспективы дальнейших исследований. Изучение психоэмоционального состояния беременных женщин, которые обратились в женскую консультацию по поводу прерывания беременности, показало наличие высоких показателей ситуативной и личностной тревожности. Коррекция психоэмоционального состояния беременной женщины при наступлении незапланированной беременности является необходимой, поскольку может уменьшить тревожность, предупредить аффективный тип мышления и принятия решений, может способствовать сохранению беременности и профилактике постабортного синдрома.

Тема постаборного синдрома редко обсуждается в специальной и научнопопулярной литературе и требует дальнейших исследований. Очевидно, что гуманистические тенденции современного общества нацеливают женщин на сохранение беременности, даже в случае вероятного рождения больного ребенка с генетическими и другими аномалиями. Однако, практика консультаций показала, что психоэмоциональное состояние беременной часто 
становится причиной абразио, что влечет за собой появление постабортного синдрома, эмоциональных страданий в течение всей жизни. Следовательно, психологическая коррекция необходима для стабилизации психоэмоционального состояния беременных, их осознанного, ответственного поведения и профилактики развития постабортного синдрома. Данная тематика требует дальнейших исследований, повышения уровня психологической культуры и духовности общества, совершенствования стратегии и тактики психологического консультирования беременных.

\section{Список використаних джерел}

1. Міненко Д. Аборт: легалізація чи заборона / Д. Міненко //Наука онлайн: Міжнародний електронний науковий журнал - 2018. - №5. [Електронний pecypc]. - режим доступу: https://nauka-online.com/ua/publications /yurisprudentsiya/2018/5/abort-legalizatsiya-ili-zapret/

2. Черевко К. О. Генезис законодавства про незаконне проведення аборту/О. К. Черевко // Вісник Харківського національного університету імені В. Н. Каразіна, 2013.- № 1082.- Серія «ПРАВО», Вип. № 16.- [Електронний ресурс]. режим доступу: file://C:/Users/Lenovo/Downloads/VKhIPR_2013_1082_16_42.pdf

3. Абдуллаходжаєва М.С. Центральна нервова система при вагітності / М. С. Абдуллаходжаєва, Н. П. Маджидов, А. Б. Погорєлова.-М.:Медицина, 2011.-92 с.

4. Абрамченко В.В. Безпечне материнство (Фізична досконалість жінки) / В.В. Абрамченко.- СПб.: ІАГ РАМН ім. Д.О. Отта, 1997.- 240 с.

5. Саввіна О. В. Причини легалізації абортів у XX ст. і сучасні дебати про моральну допустимість абортів / О. В. Саввіна // Психолог. - 2014.- № 3.- С. 221 243. 
6. Брутман В. I. Психологічні феномени, що виникають у зв'язку 3 небажаною вагітністю / В. І. Брутман // Психологія сьогодні.- Вип.4.- 2007.c. $150-151$.

7. Брутман В. I. Формування прив'язаності матері до дитини в період вагітності / Брутман В. І., Радіонова М. С. // Питання психології. - 2009. - №3. C. 38 - 47.

8. Спілбергер Ч. Тест ситуативної та особистісної тривожності / Ч. Спілбергер, Ю. Л. Ханін // [Електронний ресурс]. - режим доступу http://www.vashpsixolog.ru/psychodiagnostic-school-psychologist/69-diagnosisemotional-and-the-personal-sphere/190-scale-of-self-charles-spielberger-hanin

9. Філіппова Г. Г. Материнство і основні аспекти його дослідження в психології / Г. Г. Філіппова // Питання психології, 2001, № 2, с. 22-37.

\section{References}

1. Minenko, D. (2018), “Abortion: Legalization or Prohibition”, Nauka onlayn: Mizhnarodnyy elektronnyy naukovyy zhurnal.- vol. 5 [Online], available at:: https://nokia-online.com/ua/publications/yurisprudentsiya/2018/5/abort-legalizatsiyaili-zapret/, Uk.

2. Cherevko, K.O.(2013), "Genesis of illegal abortion legislation", Visnyk Kharkivs'koho natsional'noho universytetu imeni V. N. Karazina, Seriya «PRAVO».vol. 1082 (16), Uk.

3. Abdallahodzhayeva, M. S. Majidov, N. P. Pogopelov, A. B. (2011), Tsentral'na nervova systema pry vahitnosti [Central nervous system during pregnancy], Medicine, Moskow, Ru.

4. Abramchenko, V. V. (1997), Bezpechne materynstvo (Fizychna doskonalist' zhinky) [Safe motherhood. (Physical perfection of women)], IAH RAMN im. D.O. Otta, St. Petersburg, Ru. 
5. Savvina, O.V. (2014), "Causes of legalization of abortions in the twentieth century and contemporary debates about the moral admissibility of abortions", . Psykholoh, vol. 3, pp. 221-243, [Online], available at: http://e-notabene.ru/pp/article_ 12657.html, Ru.

6. Brutman, V. I. (2007), "Psychological phenomena arising from unwanted pregnancy”, Psykholohiya s'ohodni, vol. 4, pp.150-151, Ru.

7. Bputman, V. I. Radionova, M. S. (2009), "Fopmification of the mother's attachment to the child in the period of the pregnancy", Voprosy psichologii, vol. 3, pp. $38-47, \mathrm{Ru}$.

8. Spielberger, C. Hanin, Yu. L., Test sytuatyvnoyi ta osobystisnoyi tryvozhnosti [The test "Diagnosis of situational and personality anxiety] [Online], available at:: http://www.vashpsixolog.ru/ psychodiagnostic-school-psychologist/69-diagnosisemotional-and-the-personal-sphere/190-scale-of-self-charles-spielberger-hanin, Ru.

9. Filippova, G. G. (2001), "Maternity and the main aspects of his research in psychology", Voprosy psichologii, vol. 2, pp. $22-37$, Ru. 